\title{
MATHEMATICAL MODEL FOR THE HEAT EXCHANGE OF GREENHOUSE AND SOLARIUM SOIL IN THE PLANT ROOT AREA
}

\author{
Petru CÂRDEI, National Institute of Research - Development for Machines and Installations designed to Agriculture and Food \\ Industry - INMA, 6 Ion Ionescu de la Brad, sector 1, Bucharest, Romania, petru cardei@yahoo.com \\ Dragoș MANEA, National Institute of Research - Development for Machines and Installations designed to Agriculture and Food \\ Industry - INMA, 6 Ion Ionescu de la Brad, sector 1, Bucharest, Romania, manea_dragos_05@yahoo.com (corresponding author)
}

\begin{abstract}
This paper proposes a structural mathematical model of heat exchange into the soil of a solarium. The model investigates the possibility of a rational choice of the cooling water transit time through the pipeline network located in the plant root area. Also, the size of the cooled root area is roughly determined, according to the temperature of the cooling fluid. At the same time, the model provides information on the degree of soil cooling, meaning the ratio between the average soil temperature in the cooled root area and a reference temperature, for example the temperature indicated by a sensor into the soil, at a distance fixed to the root axis. The model considered is a plan one. Geometric is considered a section through the soil, perpendicular to the axis of the pipe carrying the cooling fluid. The soil, the copper pipe and the water are the components of the model. The finite elements for meshing are flat, triangular. This simple model prepares a three-dimensional complex approach and has, as a preparation, a unidimensional model. Obviously, this model provides some start-up indications for achieving the physical model and content of the process parameter set. After its realization, the physical model will be used for the optimal control of the cooling process in the radicular area, but also for the validation and the improvement of the theoretical model.
\end{abstract}

Keywords: heat exchange, mathematical model, root area.

\section{INTRODUCTION}

The problems of simulation of heat exchange processes have increased in the last decades and in the field of agriculture, together with increasing their complexity (Cârdei and Manea, 2017; Gauthier et al., 1997; Hatfield et al., 2015; Kimball, 1973; Rodríguez et al., 2015; Vancea, 2008; Yildiz, 1993; Zhu et al., 1998). Specialty literature has increased in volume over the past decades and due to the effects in agriculture of what we understand as climate change (Kang et al., 2009). The problems encountered in this paper seem to be in the classical category of heat exchange, often found in the literature (Badea, 2004). Engineer requirements that design technological processes in agriculture and food industry require complex results that go beyond the gross results of structural analysis programs that solve heat-exchange problems in complex areas. The aim of this paper was to develop a structural mathematical model of heat exchange into the soil of a solarium. The model gives the possibility of a rational choice of the cooling water transit time through the pipeline network located in the plant root area.

\section{MATERIAL AND METHOD}

The physical model of the phenomenon is the soil in the root area inside a solar, crossed by a pipeline network that facilitates the transport of water for the superficial cooling of the soil during the summer. This network has the role of cooling the soil on hot days, especially in the root zone.

In figure 1 is a graphical representation of the physical model of the solar with the soil containing the water cooling system (lower, at a depth of 2 meters), respectively the cooling system of the soil (above, at a depth of 0.2 meters below the surface of the soil). A picture of the real system is shown in figure 2.

Copyright (C) 2017 The Authors. Published by Aleksandras Stulginskis University. This is an open-access article distributed under the terms of the Creative Commons Attribution License (CC-BY 4.0), which permits unrestricted use, distribution, and reproduction in any medium, provided the original author and source are credited. 


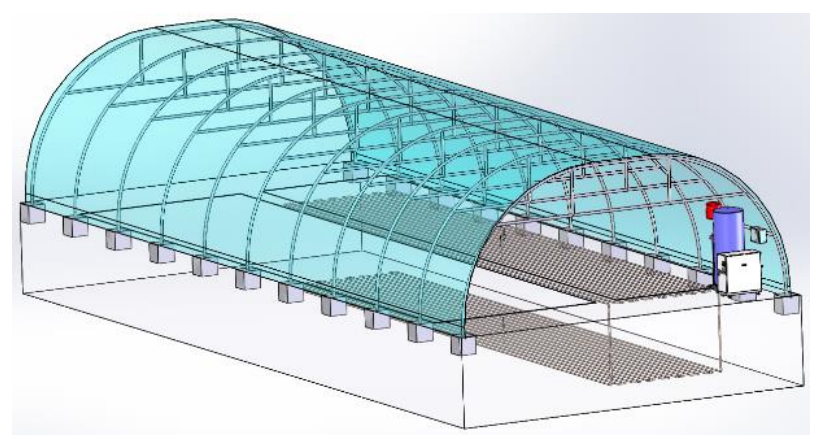

Figure 1. Outline of the physical model of the solar

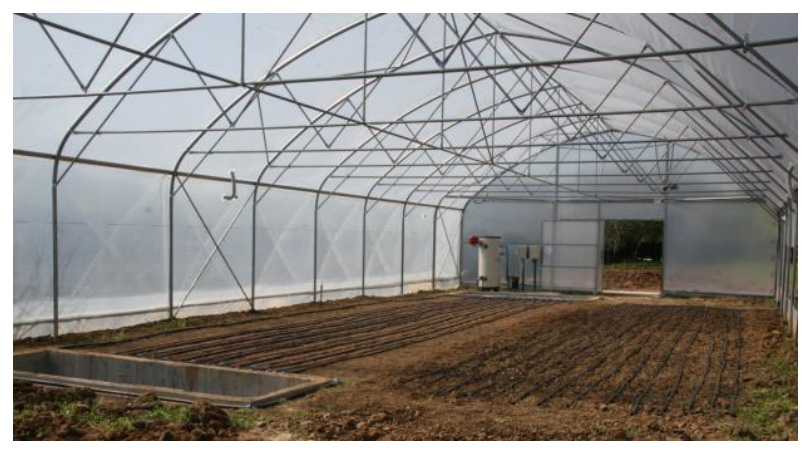

Figure 2. The real system

The structural model operates with continuous body models for all three components: water (coolant), copper (pipe) and soil. The list of physical properties of the materials used in the construction of the heat exchange structural model is shown in Table 1.

Table 1. Physical properties of the materials used in the structural model

\begin{tabular}{|c|c|c|c|}
\hline \multirow{2}{*}{ Material } & Density, $\mathrm{kg} / \mathrm{m}^{3}$ & Thermal conductivity, & $\mathrm{J} /(\mathrm{kg} \mathrm{K})$ \\
& & $\mathrm{W} /(\mathrm{m} \mathrm{K})$ & 4192 \\
\hline Water & 999.8 & 0.6065 & 390 \\
\hline Copper & 8960 & 401 & 1380 \\
\hline
\end{tabular}

The geometry of the structural model appears in Figure 3. The model is composed of a soil volume with a square cross-sectional area with a side of $0.4 \mathrm{~m}$, a copper pipe having an inner diameter of $0.022 \mathrm{~m}$. In the detail in Figure 3 can be better observed the thickness of the pipe wall, which is $0.0007 \mathrm{~m}$.

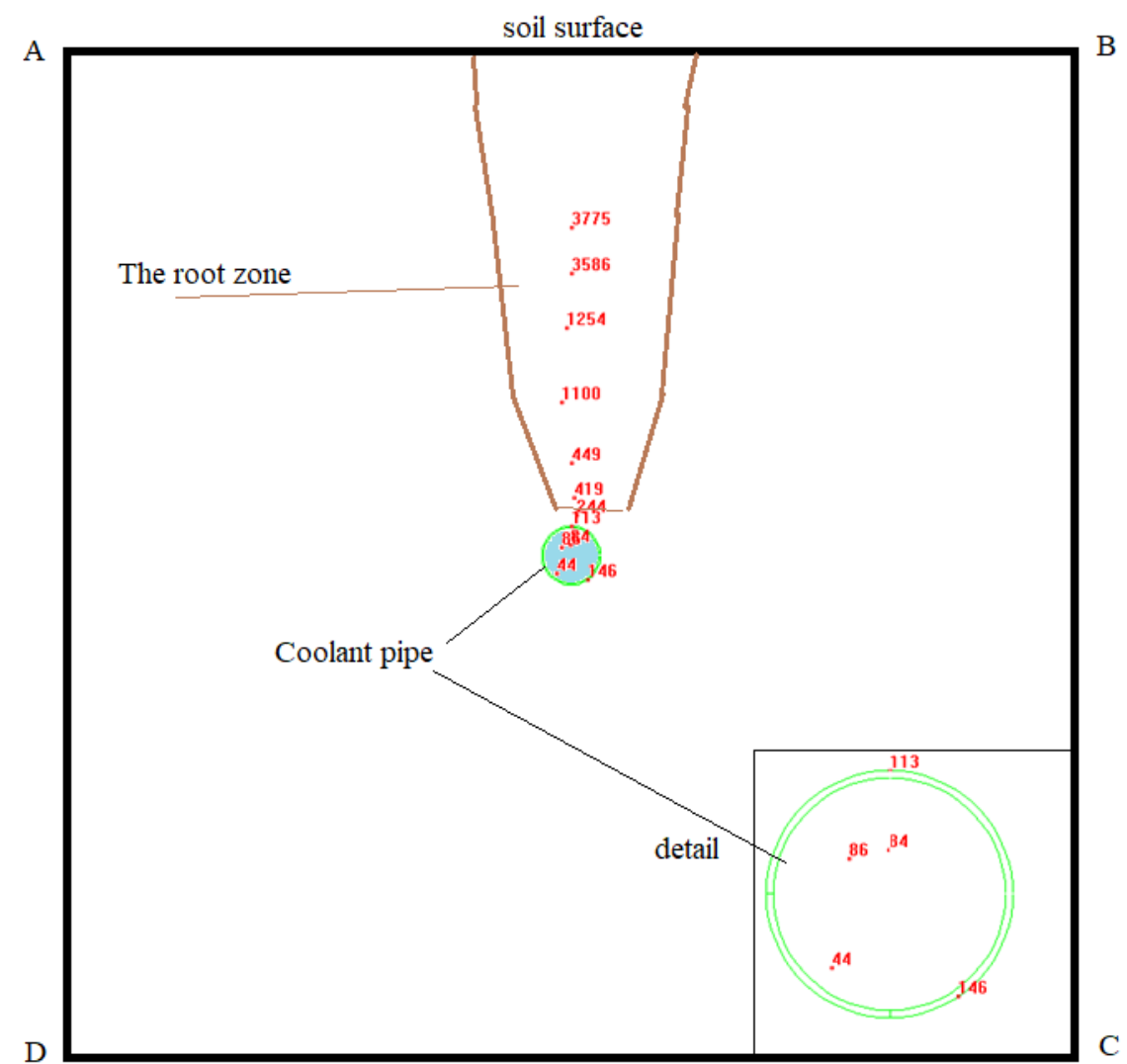


Figure 3. The geometry of the structural model and the locations of the nodes (in red) for which the temperature variation curves in time were represented in figures 6 and 7

The initial conditions of the study were the following:

- inside the pipe, the temperature with which the water leaves the cooling system, $10^{\circ} \mathrm{C}$, was considered for the results in Figures 4 - 7;

- the soil inside the boundary and in the walls of the pipeline, it was considered constant temperature at $30^{\circ} \mathrm{C}$.

Boundary conditions were also considered: $35^{\circ} \mathrm{C}$ on line $\mathrm{AB}$ (soil surface), $30^{\circ} \mathrm{C}$ on $\mathrm{AD}$ and $\mathrm{BC}$ lines, respectively $25^{\circ} \mathrm{C}$ on the $\mathrm{CD}$ line.

The structural model was meshed with 8614 triangular elements SHELL3 with three nodes, from the finite element library of the COSMOS / M 2.8 structural analysis program (COSMOSM User's Guide, 2003). The number of nodes in the structural model is 4436 . The model has been solved in a transient mode, for a very long time relative to the time that the water normally transits the system, which is $7200 \mathrm{~s}$.

The depths of control nodes, whose position is graphically indicated in Figure 3, are shown numerically in Table 2. The depth of each node is the distance between the node and the soil surface represented by the AB line. A detail with the nodes in the field of the cooling agent and at the boundary between the field occupied by the soil and the field occupied by the copper pipe wall, is also given in Figure 3.

Table 2. The depths of the nodes in which the temperature variation in time in figures 1 and 2

\begin{tabular}{|c|c|c|c|}
\hline & Depth, cm & Node & Depth, cm \\
\hline 244 & 18.42 & 3775 & 8.04 \\
\hline 113 & 18.88 & 3586 & 11.20 \\
\hline 84 & 19.58 & 1254 & 13.93 \\
\hline 86 & 19.67 & 1100 & 16.35 \\
\hline 44 & 20.70 & 449 & 14.70 \\
\hline
\end{tabular}

\section{RESULTS AND DISCUSSIONS}

All the results obtained can be used both for descriptive purposes (to explain and facilitate the understanding of the phenomenon) and for application purposes (for process control and rationalization, maybe optimization). The analysis provides more results than those presented in this article. We only present results that are strictly interested in applications.

In Figure 4 is a graphical representation of the distribution of the thermal field in the soil section with the pipe centered at the depth of $0.2 \mathrm{~m}$, at the initial time $\mathrm{t}=0$. It is possible to check the initial conditions. This section would correspond to the water inlet area in the soil cooling circuit.

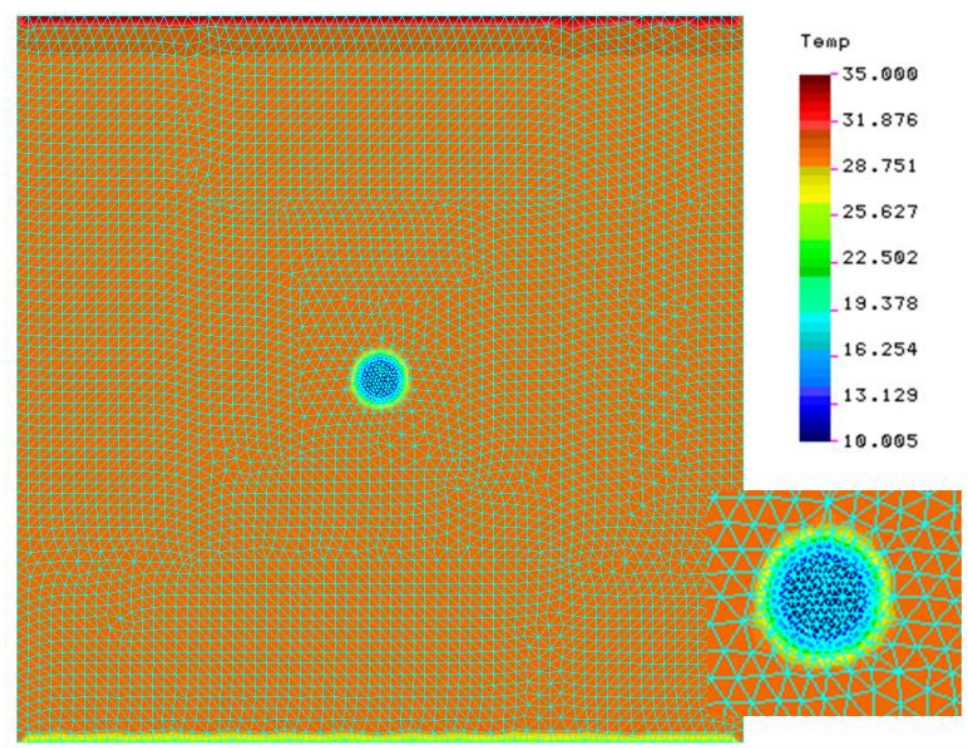

Figure 4. The temperature distribution in the cooling water inlet section in the soil top layer, the image corresponding to the first step of the analysis, $10 \mathrm{~s}$ 
In Figure 5 is graphically presented the distribution of the thermal field in the soil section with the pipe centered at the depth of $0.2 \mathrm{~m}$ at the end time of the simulation, $\mathrm{t}=7200 \mathrm{~s}$ ( 2 hours).

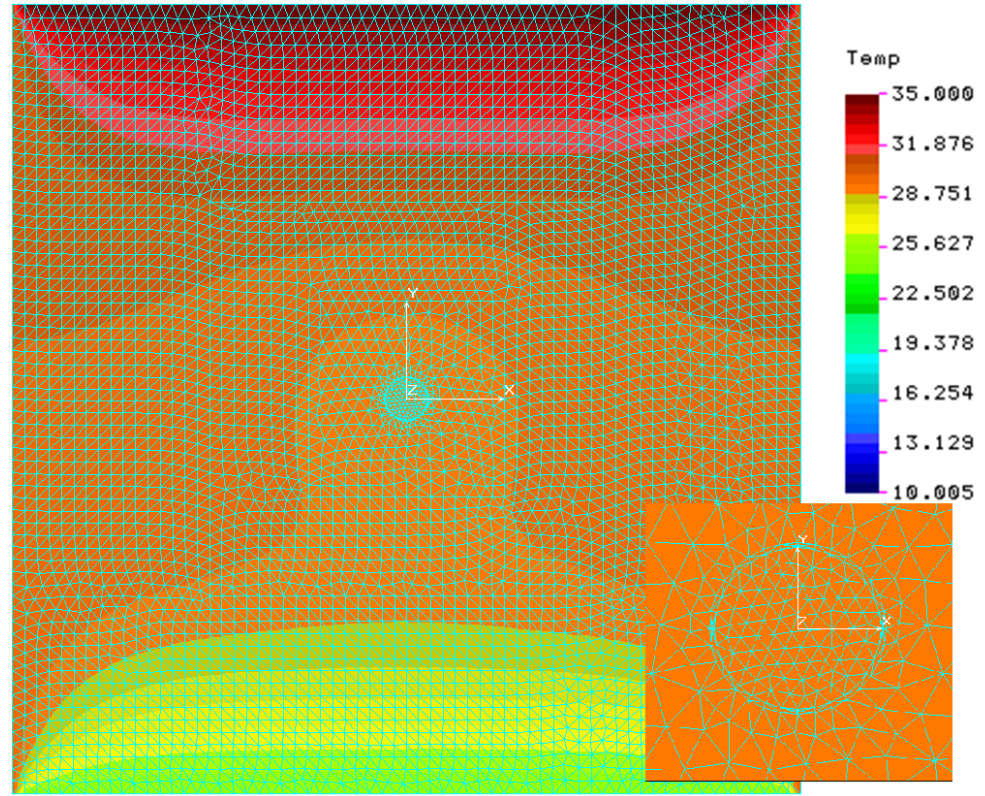

Figure 5. Temperature distribution in cooling water inlet section in soil top layer, final time, $7200 \mathrm{~s}$

In the soil section perpendicular to the direction of the pipe axis, in Figure 5, the probable root area is also outlined. This area should be cooled to a temperature within a range indicated by agro-technicians. This safety interval for the plant depends on the crop and the environmental conditions imposed by the solar climate. Also in figure 5 are shown the positions in the soil section cooled by the buried pipe at the depth of $0.2 \mathrm{~m}$, of the nodes in which the graphical representation of the time variation of the temperature was required. Control nodes are also placed inside the range occupied by the cooling agent. These nodes were used to plot the temperature variation over time in different areas of the cooling field.

In Figures 6 and 7 is represented the temperature variation in the control nodes, whose depths from the soil surface are given in Table 2. In Figure 6 is the temporal variation in all selected nodes in the cooling field, plus only the node 244 in the field occupied by the soil. The temporal variation of temperature in the soil at node 244 was placed in Figure 6 to highlight the difference in behaviour of the thermal field in the two areas (of the cooling agent and of the soil). In Figure 7 is the temporal variation of the thermal field in the nodes located in the area occupied by the soil in the structural model. Nodes whose temporal temperature variation is given in Figure 7, are nodes located in the root area and highlight the extension of this area starting from the wall of the pipe to the soil. 


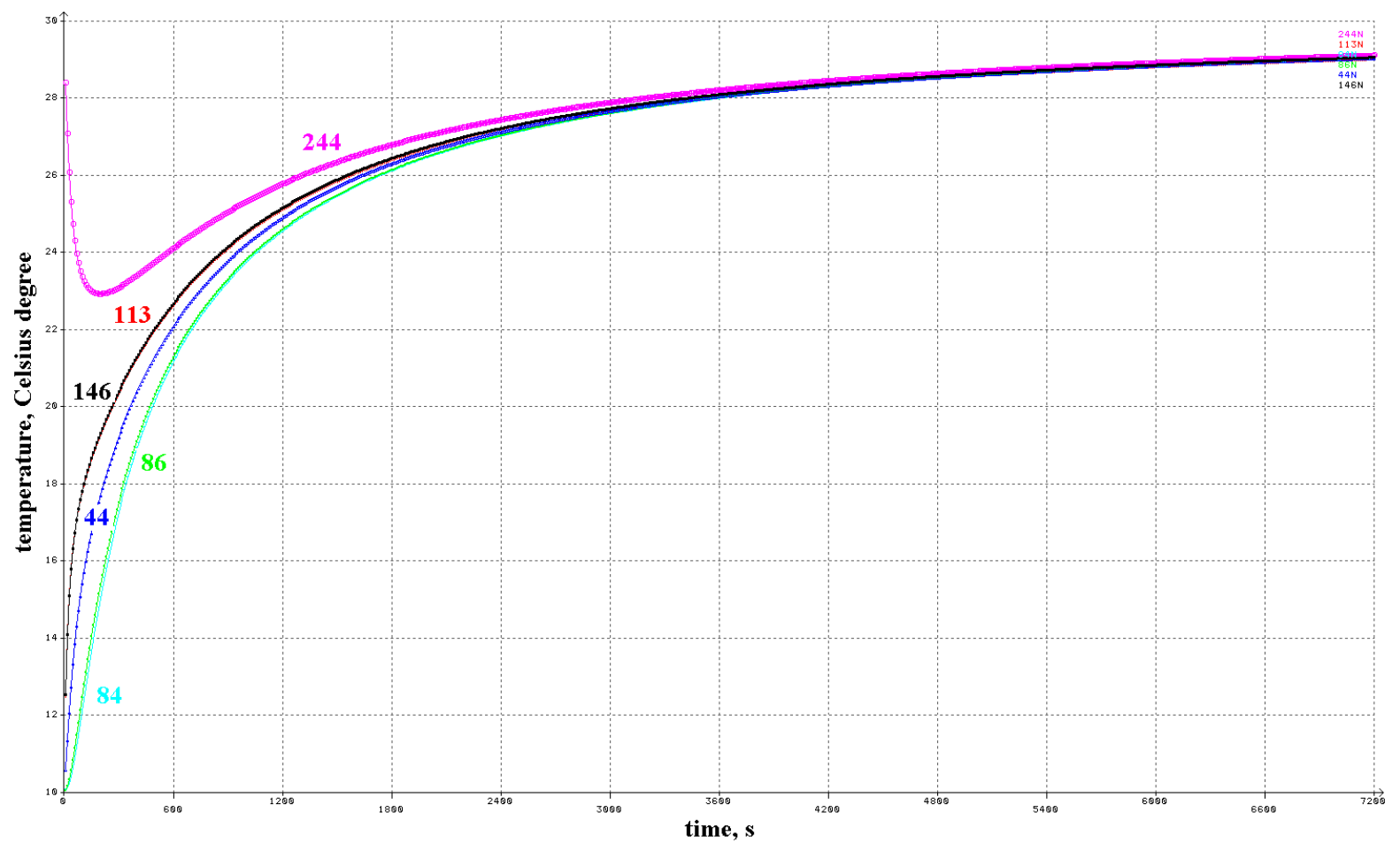

Figure 6. Temperature variation in time in the nodes $244,113,84,86,44,146$

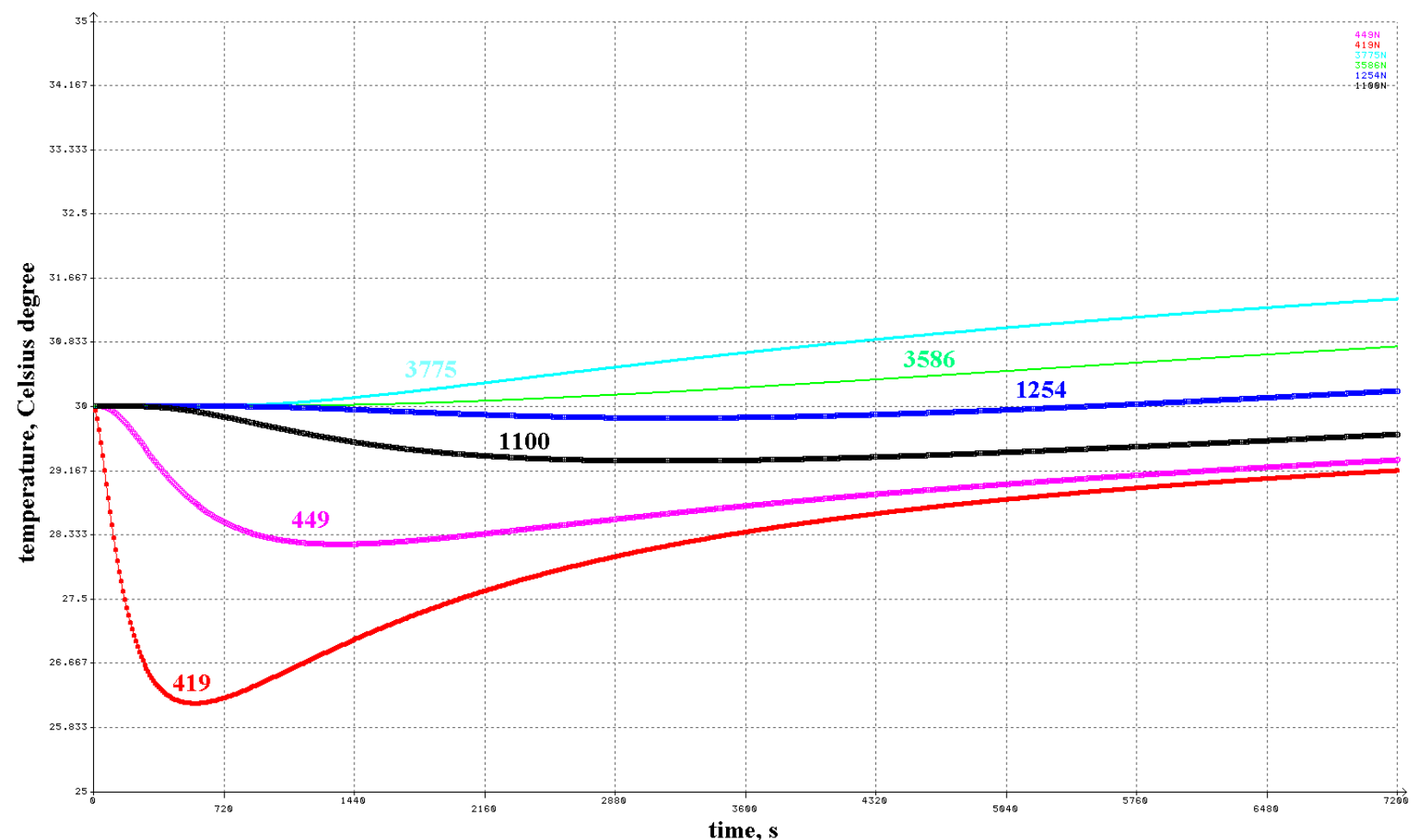

Figure 7. Temperature variation in time in the nodes 419, 464, 1069, 1161, 1223, 1285

From a physical point of view, the simulated phenomenon represents the propagation of a damped thermal waves in the soil in the vicinity of the pipeline, simultaneously with continuous water heating in the pipeline.

From a descriptive point of view, the model behaves satisfactorily. It is observed that near the initial moment, the soil temperature in the area considered is $30^{\circ} \mathrm{C}$, and in the area of the cooling agent and a very small neighborhood the temperature varies around $10^{\circ} \mathrm{C}$ (step 1 of the analysis, time $\mathrm{t}=10 \mathrm{~s}$, Figure 4 ). At the final analysis time, $\mathrm{t}=7200 \mathrm{~s}$, one can observe the homogenization of the thermal field between the values fixed on the border. The cooling fluid also reaches the ambient temperature (about $30^{\circ} \mathrm{C}$, Figure 5).

The propagation of the cooled cooling wave from the pipe through which the cooling agent flows to the ground is evident in the graphical representations in Figures 6 and 7. The temperature in the lower radicular nodes (the root zone of the points near the coolant pipe) decreases for a while, then increases and goes asymptotically to the equilibrium temperature, also taking into account the boundary condition on the soil surface (temperature $35^{\circ} \mathrm{C}$ ). 
Considering the initial and limit temperatures chosen for this simulation and using the graphical representation of Figure 7, it can be estimated that the cooling is felt into the soil at depths greater than $0.11 \mathrm{~m}$. Cooling over two degrees (reaching about $28^{\circ} \mathrm{C}$, compared to $30^{\circ} \mathrm{C}$, the temperature at the beginning of the cooling process) is obtained for depths exceeding $0.16 \mathrm{~m}$.

In the node 244 , at a depth of more than $0.18 \mathrm{~m}$, a cooling of approximately 7 degrees $\left(23^{\circ} \mathrm{C}\right)$ is obtained. It is noticed that the cooling is less intense and reaches as late as the point in the soil is farther away from the coolant pipe. At the initial temperatures considered and the specified boundary conditions, it can be considered, for example, that after about $200 \mathrm{~s}$ (the time at which the temperature reaches the minimum value in the node 244), the water has to be replaced. This means that the water running time through the upper network pipe must be less than 200 seconds. If it is assumed to be a linear pipe of $240 \mathrm{~m}$, then the flow rate in the pipeline of the cooling fluid should be $1.2 \mathrm{~m} / \mathrm{s}$. This speed is achievable considering a maximum flow rate of $3.24 \mathrm{~m}^{3} /$ hour, the flow rate at which the pipes are handled taking into account the allowable pressure.

Anyway, if the circulation takes place in one direction, the parcel that the cooling installation serves, there will be some possibly large inhomogeneities. The soil area adjacent to the cold water inlet point in the upper network will cool off considerably, more intensively than the water outlet area in the same network.

\section{CONCLUSIONS}

The results obtained in the numerical simulation described in this paper allow estimation of the following application results:

1. Maximum distance to which the temperature difference available between the cooling source and the soil allows cooling;

2. The amount of cooling obtained by the distance from the outer walls of the pipe through which the coolant circulates;

3. The time that the water cooling capacity of the pipe becomes insufficient and, starting from this time, the possibility of establishing the flow rate of the coolant through the pipe.

The development of soil cooling solutions in the root area, in accordance with agro technical indications, to improve the above-mentioned non-uniformities, should allow either fluid circulation in opposite directions or dual cooling networks. The study of such systems will possibly be done on three-dimensional or mixed models, but the cost of their physical realization may be very high.

\section{ACKNOWLEDGEMENTS}

This work was funded by the The Ministry of Research and Innovation, within the projects PN 16240101 - Intelligent system for condensation irrigation in greenhouses and solariums and PN 16240103 - Advanced computer and digital research of conception and development, in order to efficiency the intelligence technology systems for agricultural works within the Program NUCLEU 2016 - 2017.

\section{REFERENCES}

1. Badea, A.A. 2004. Initiation in Heat and Mass Transfer. Romanian Academy Publishing House.

2. Cârdei, P., Manea, D. 2017. Convergence study for a heat transfer problem. Available at https://www.researchgate.net/publication/317094072_Convergence_study_for_a_heat_transfer_problem .

3. Gauthier, C., Lacroix, M., Bernier, H. 1997. Numerical simulation of soil heat exchanger-storage systems for greenhouses. Solar Energy, Vol. 60, Issue 6, pp. 333-346. https://doi.org/10.1016/S0038-092X(97)00022-4

4. Hatfield, J.L., Prueger, J.H. 2015. Temperature extremes: Effect on plant growth and development. Weather and Climate Extremes, Vol. 10, Part A, pp. 4-10. https://doi.org/10.1016/j.wace.2015.08.001

5. Kang, Y., Khan, S., Ma, X. 2009. Climate change impacts on crop yield, crop water productivity and food security - A review. Progress in Natural Science, Vol. 19, Issue 12, pp. 1665-1674. https://doi.org/10.1016/j.pnsc.2009.08.001

6. Kimball, B. A. 1973. Simulation of the energy balance of a greenhouse. Agricultural Meteorology, Vol. 11, pp. 243-260. https://doi.org/10.1016/0002-1571(73)90067-8

7. Rodríguez, F., Berenguel, M., Guzmán, J.L., Ramírez-Arias, A. 2015. Modeling and Control of Greenhouse Crop Growth. Advances in Industrial Control, Springer International Publishing Switzerland. DOI 10.1007/978-3-319-11134-6

8. Vancea, C. 2008. Contributions to the management of geothermal energy systems: case study. PhD Thesis, Faculty of Electrical Engineering and Information Technology, Oradea University, Romania.

9. Yildiz I. 1993. Simulation of greenhouse microclimates and environmental control strategies using a rankine cycle heat pump. Dissertation for the Degree Doctor of Philosophy, The Ohio State University. https://etd.ohiolink.edu/rws_etd/document/get/osu1145453202/inline

10. Zhu, S., Deltour, J., Wang, S. 1998. Modeling the thermal characteristics of greenhouse pond systems. Aquacultural Engineering, Vol. 18, pp. 201-217. https://doi.org/10.1016/S0144-8609(98)00031-4

11. COSMOSM User's Guide 2003. Structural Research and Analysis Corporation (SRAC). 